\title{
The relationship between speech, oromotor, language and cognitive abilities in children with Down's syndrome.
}

\begin{abstract}
.
Background: Children and young people with Down's syndrome (DS) present with deficits in expressive speech and language, accompanied by strengths in vocabulary comprehension compared to nonverbal mental age. Intelligibility is particularly low, but whether speech is delayed or disordered is a controversial topic. Most studies suggest a delay, but no studies explore the relationship between cognitive or language skills and intelligibility. This study sought to determine whether severity of speech disorder correlates with language and cognitive level and to classify the types of errors, developmental or non-developmental, that occur in the speech of children and adolescents with DS.

Methods \& Procedures: 15 children and adolescents with DS (aged 9 to 18) were recruited. Participants completed a battery of standardised speech, language and cognitive assessments. The phonology assessment was subject to phonological and phonetic analyses. Results from each test were correlated to determine relationships.

Outcome \& Results: Individuals with DS present with deficits in receptive and expressive language that are not wholly accounted for by their cognitive delay. Receptive vocabulary is a strength in comparison to expressive and receptive language skills, but it was unclear from the findings here whether it is more advanced compared to non-verbal cognitive skills. The majority of speech errors were developmental in nature but all of the children with DS showed at least one atypical or non-developmental speech error.
\end{abstract}


Conclusions: Children with DS present with speech disorders characterised by atypical, and often unusual errors alongside many developmental errors. Lack of correlation between speech and cognition or language measures suggests that the speech disorder in Down's syndrome is not simply due to cognitive delay. Better differential diagnosis of speech disorders in DS is required, allowing interventions to target the specific disorder in each individual.

\section{What this paper adds}

\section{What is already known on this subject}

Previous studies have shown that compared to their nonverbal mental age, children and young people with Down's syndrome (DS) present with deficits in expressive speech and language, accompanied by strengths in vocabulary comprehension. Speech intelligibility is particularly impaired, and most studies suggest that this is the result of a delay rather than a disorder.

\section{What this study adds}

Children and adolescents with Down's syndrome present with deficits in receptive and expressive language that are not wholly accounted for by their cognitive delay. No correlation was found between speech and language measures or speech and cognition measures, suggesting that the cause of the speech disorder is not merely cognitive or language delay. Children with Down's syndrome present with speech disorders characterised by often unusual and atypical errors alongside many developmental errors. 


\section{Introduction}

Down's syndrome (DS) is the most common cause of intellectual impairment, affecting 1 in every 732 live births (Canfield et al., 2006). It is a genetic disorder, caused in most cases $(95 \%)$ by the presence of an extra chromosome in the $21^{\text {st }}$ pair (trisomy 21 ) and in fewer cases by mosacism (1\%) or translocation (4\%). The degree of cognitive impairment varies widely in people with DS, but $85 \%$ of people with DS present with mild to moderate intellectual impairment, achieving IQ scores of between 40 and 60 (Roizen, 2002), with a minority of people with DS presenting with severe cognitive impairment (IQ<40). Individuals with DS present with a specific behavioural phenotype which differs from other syndromes. Theoretically, it is important to know which aspects of the behavioural phenotype are specific to DS in order to learn more about the genetic profile of the syndrome (Abbeduto et al. 2001). Clinically, this is important because knowledge about which areas of functioning are likely to be most or least impaired enables clinicians to design interventions that target areas of weakness and utilise areas of strength in their teaching methods. Similarly, it is important to know whether areas of functioning are delayed or disordered. A disordered profile may suggest that spontaneous improvements are less likely and that specific interventions may have to be designed.

Recent research suggests that children and young people with Down's syndrome (DS) present with deficits in expressive speech and language, and strengths in vocabulary comprehension compared to nonverbal mental age (Chapman, 2006). Speech intelligibility is particularly impaired (Rondal and Edwards, 1997) and a survey of families by Kumin (1994) revealed that over $58 \%$ of parents reported that their children 
had difficulty being understood frequently, with a further $37 \%$ having difficulty being understood sometimes, by people outside of their immediate circle. Whether speech is delayed or disordered is a controversial topic, but most studies have suggested a delay (Van Borsel, 1996), or a delay with some elements of disorder (Roberts et al., 2005).

\section{Speech Disorder in DS}

The speech disorder in DS is thought to result from impairments in almost all of the systems required for successful speech. In addition to specific behavioural characteristics, people with DS present with a specific anatomical profile that may affect speech production (Spender et al. 1995; Miller, Leddy and Leavitt, 1999). The ability to create the precise articulations required for speech may be influenced by a smaller than average oral cavity (which gives the impression of a larger tongue), hypotonia of muscles around the mouth, fusion of lip muscles and extra lip musculature. Differences in nerve innervation contribute to reduced speed and range of movement (Miller and Leddy, 1998), suggesting that dysarthria may be a factor in reduced intelligibility.

An increased incidence of hearing impairment in the DS population (Roizen, 1997) may contribute to the speech and language problems. Chapman (1998) estimates that hearing loss accounts for only 4 to $7 \%$ of the variance in grammar comprehension whereas Jarrold, Baddeley and Philips (2002) found no relationship between language and hearing levels. The differences may be due to the characteristics of the participants, Laws (2004) found that hearing did not contribute significantly to expressive language 
scores of participants who were able to produce intelligible narratives. However, severity of hearing loss, as well as other language and memory measures, did differentiate these participants from those who were unable to produce an intelligible narrative.

In addition to the anatomical differences, people with Down's syndrome perform poorly in most areas of motor functioning (Frith and Frith, 1974; Spender et al., 1995; Spano et al., 1999) and particularly in motor control in speech production (Kumin, 1994). Barnes et al (2006) found that boys with Down's syndrome showed significantly lower levels of lip, tongue, velopharynx, larynx and coordinated speech function than typically developing boys, matched for nonverbal mental age, and lower levels of coordinated speech movements than boys with Fragile X (another common cause of intellectual disability), also matched for nonverbal mental age.

A recent survey by Kumin (2006) showed that the majority of children with DS showed signs of dyspraxia (childhood apraxia of speech) but this disorder is rarely diagnosed in DS. Clearly more research is needed to clarify the nature of the speech disorder in DS in order to design appropriate interventions.

\section{Phonological Delay versus Disorder}

Differences in anatomy and motor functioning do not in themselves account for the severity of speech disorder often evidenced in DS (Laws and Bishop, 2004). There have been many studies which have suggested that the speech difficulties are a result of a phonological delay, following the same pattern of development as normal speakers but more slowly (e.g. Stoel-Gammon, 1980; Van Borsel, 1996). Others have suggested a 
phonological delay with some elements of disorder, following an idiosyncratic developmental pattern, different from normal speakers (Roberts et al., 2005).

The nature of the phonological errors is subject to considerable controversy. Van Borsel (1996) argues strongly that phonology is delayed in DS. Rather than matching participants with DS (aged 15;4-28;3) to typical children on cognitive measures, his control group consisted of children young enough still to be in the process of phonological acquisition (aged 2;6-3;4). Many of the speech errors were similar between the two groups and the phonemes in error were significantly similar. However there was a difference between groups in the frequency of distortions, with additional distortions found in the DS group described by Van Borsel as, for example, 'denasalisation', 'dentalisation' and 'wet'. Despite this, Van Borsel concluded that phonology was delayed in DS. This conclusion is problematic since distortions are usually thought of as phonetic rather than phonological errors, although he acknowledged the uncommon distortions present in the DS speakers may relate to anatomical differences.

Dodd and Thompson (2001) argue convincingly that the speech disorder in DS is not simply a delay but a disorder of phonological acquisition. They compared children with DS to children with inconsistent phonological disorder matched for gender and socio-economic status. As groups, there was no significant difference between percentage consonants correct, confirming that both groups had a similar severity of speech disorder. Both groups of children were inconsistent when producing the same set of words on three different occasions. All of the children with DS were inconsistent, with a mean inconsistency score of $67 \%$. In comparison, a third group of children with a straightforward delay in phonology had inconsistency ratings of less than $20 \%$, 
suggesting that the inconsistency in DS is not due to delay. Dodd and Thompson suggest that this inconsistency has a different cause than that seen in children who have inconsistent phonological disorder but are otherwise typically developing. They suggest that underspecified, or "fuzzy", phonological representations may be responsible for the inconsistency or that a difference in language learning environments means that inconsistency is inadvertently reinforced.

The study by Dodd and Thompson presents compelling evidence that the speech disorder in DS is not merely a result of a cognitive disability. If indeed the speech disorder is not related to cognitive ability then we would expect to find no correlation between severity of speech disorder and cognitive level. However, most research does not address the question of whether severity of speech disorder is related to language or cognitive level. Anecdotal reports from parents suggest that the most unintelligible children are not necessarily the children with the most severely impaired language or cognitive skills. It was therefore the principal aim of this study to determine whether severity of speech disorder correlates with language and cognitive levels and to describe the types of errors, developmental or non-developmental, that occur in the speech of children and adolescents with DS. The use of standardised tests enabled us to compare the children with DS to norms for typical children without the addition of a control group. In terms of the phonological analysis, the types of processes found in typical development are well documented in the literature, so again a control group was not required. A second aim was to describe speech, language and cognitive profiles in children and adolescents with DS to confirm whether the participants in this study 
conform to the notion that people with DS present with deficits in expressive language and strengths in receptive vocabulary.

\section{Method}

\section{Participants}

Fifteen children and young people with Down's syndrome (DS, trisomy 21) living in the central belt of Scotland participated in the study. The children were aged 9.83-18.75 years (mean 14.30, SD 3.07), and the group comprised 12 boys and 3 girls. Children were excluded if any of the following criteria applied: (1) English was not the child's first language and/or not the main language of the home; (2) there was evidence of severe hearing loss (aided threshold $<40 \mathrm{~dB}$ ); (3) the child was not able to use single words (i.e. no speech); (4) there was a co-morbid diagnosis of autism; (5) cognitive ability was less than an age equivalent of $2 ; 6$ years.

A further five children were excluded from the study, three younger children (aged 9, 9 and 10) had full-scale mental age equivalents less than 2;6, one had no speech and one had excellent speech, making him unsuitable for the intervention study that the current study was part of. Some of the children who took part in the study were members of a database of individuals with DS who were willing to take part in research projects. Other participants were recruited by advertising the study via a national charity. Since the participants were required to attend several times (for the intervention phase of the larger project), the group may represent those children and young people for whom intelligibility is a particular issue and who are able to commit to an intervention programme. Most participants had undergone recent audiological testing which confirmed their hearing status. However, to confirm adequate speech perception ability, 
all also completed and passed (scores $>83 \%$ ) the Manchester Picture Test (Hickson, 1987).

As part of a larger study investigating speech motor control, all of the children had custom-made electropalatography palates (EPG palates). EPG records the timing and location of the tongue with the hard palate. Participants were wearing their EPG palates during the recording of one of the speech tests (see below). As part of the larger study children were randomised to two treatment groups (one involving EPG as a visual feedback aid and the other with no visual feedback) and one control group. All data presented here was collected before the children were randomised to groups or received any intervention.

\title{
Standardised Assessments
}

\section{Language, speech and cognitive assessments}

\begin{abstract}
All children completed a battery of standardised speech, language and cognitive assessments. Speech and language tests were carried out by a qualified speech and language therapist; cognitive assessments were carried out by a child psychologist. Most children completed the battery in three, one-hour sessions, with breaks as requested by either the child or their carer. In order to accommodate the language and cognitive impairment typical of DS, in most cases the assessments used were standardised on much younger children. Age equivalent scores, raw scores and percentages were therefore used in the analyses.
\end{abstract}

\section{Cognitive Ability}


Cognitive ability was assessed using the full form of the Weschler Preschool and Primary Scale of Intelligence (WPPSI-IIIUK, Weschler, 2003). Verbal, performance and fullscale age equivalents (mental ages) were calculated.

\section{Receptive Vocabulary}

The British Picture Vocabulary Scales-II (BPVS-II, Dunn et al., 1997) were used as a measure of receptive vocabulary. This assessment covers a wide age range and is a wellestablished tool for measuring verbal mental age. It is a multiple-choice test in which participants must select one of four pictures to match a single word spoken by the tester.

\section{Receptive and Expressive Language}

The Clinical Evaluation of Language Fundamentals-Preschool UK (CELF-P, Wiig, Secord and Semel, 1992) was used to measure receptive and expressive language. This test allows calculation of receptive, expressive and total language (an average of the receptive and expressive) age equivalents. Receptive language is assessed in three subsets:

- Linguistic Concepts: Comprehension of oral directions containing either early linguistic concepts, or quantifiers and ordinals, or stimuli of increasing length.

- Sentence Structure: Comprehension of spoken sentences of increasing length and structural complexity.

- Basic Concepts: Comprehension of modifiers.

Expressive language is also assessed in three subtests:

- Recalling Sentences in Context: Recall and repetition of spoken sentences of increasing length and complexity.

- Formulating Labels: Picture naming of nouns and verbs.

- Word Structure: Expression of morphological rules and forms. 


\section{Phonology}

All children completed the phonology subtest of the Diagnostic Evaluation of Articulation and Phonology (DEAP, Dodd et al., 2002). This is a measure of consonant production in single words, covering most consonants of English in word initial and final positions. The phonology subtest allows calculation of percentage consonants correct (PCC); percentage vowels correct (PVC); percentage phonemes correct (PPC) and single words/ connected speech phoneme agreement $(\mathrm{SvC})$. Audio recordings were made to allow for fine phonetic transcription. As all children were enrolled in an EPG intervention study, they were wearing EPG palates during the completion of the DEAP. However they had undergone a programme of acclimatisation whereby they wore the palate for increasing periods of time up to 40 minutes prior to the recording (the actual EPG recording was no longer than 30 mins). EPG provides useful information about tongue to palate contact and this visual information was used to aid the phonetic transcription.

Phonology: Reliability

Transcriptions from four randomly selected participants (50 words per participant, therefore transcription of 200 words in total) were subjected to inter-rater reliability on a segment by segment basis. Mean agreement was $88.22 \%$ (reliability for each of the four participants was $85.55 \%, 87.78 \%, 88.90 \%$ and $90.55 \%)$.

\section{Phonological and Phonetic Analyses}

All errors produced in the phonology subtest of the DEAP were subjected to a process analysis and classified as either typical (occurring in the speech of children aged 2;0 to $5 ; 11$ and therefore delayed) or atypical (occurring in less than $10 \%$ of typical children aged $2 ; 0$ to $5 ; 11$ ) using data from Dodd et al. (2002) and as either structural (for example 
deletions of syllables or segments) or systemic (for example substitutions). Theoretically it is important to know whether phonology is delayed or disordered. A delayed pattern may suggest that speech is developing in tandem with delayed language and cognition whereas a disordered pattern may suggest a more specific speech disorder. Whether errors are systemic or structural has important implications for therapy, structural errors can be treated using phonotactic therapy, focusing on whole word phonology.

Local dialect was taken into account, for example, in Scottish English glottalisation of word medial and final /t/ is normal, this was therefore not counted as an error. "Glottal replacement" therefore refers to instances where a child used a glottal stop in an atypical way, for example in place of a word initial stop. Although all of the children's errors were described in terms of process analyses, this does not necessarily suggest that the errors are a result of a phonological impairment. While some errors were thought to be phonological in nature, for example fronting of $/ \mathrm{k} /$ to $[t]$, other processes were more likely to be phonetic in nature, for example, lateralisation of sibilants. For the purposes of the analysis all errors were counted together. In addition to calculating the number of times a process occurred, the number of children displaying a process 3 or more times (Dodd et al. 2002) was also calculated. This enabled us to identify whether errors occurred only occasionally in a child's speech or whether they were more prevalent. It also allowed us to determine whether particular processes were common to all or most children with DS.

\section{Oromotor Function}


Oromotor function was assessed using the Robbins and Klee clinical assessment of oropharyngeal motor development in young children (RK, Robbins and Klee, 1987). In this assessment, children are required to perform speech and non-speech oral movements, which are scored as either adult-like (2 points), approaching adult-like (1 point) or absent (0). Raw scores were converted to a percentage.

\section{Intelligibility}

Previous studies of speech in DS have used parent questionnaires to rate intelligibility (Kumin 1994). We sought to use an objective method in order to quantify the severity of the unintelligibility, and to enable us to compare percentage consonants correct (from the DEAP) with more global intelligibility. Since many of the young people with DS spoke in either single words or short phrases, the Children's Speech Intelligibility Measure (CSIM, Wilcox and Morris, 1999) was chosen. The test involves a listener who is unfamiliar with the child listening to 50 (imitated) words and identifying which word was uttered from a possible 12 phonetically-similar words (for each of the 50 words). Percentage of correctly identified words was calculated.

\section{Results.}

Tables $1 \mathrm{a}$ and $1 \mathrm{~b}$ show the individual and group results for all measures, with numbers expressed as age equivalents or percentages as appropriate. Most of the children failed to meet the basal age equivalent on the DEAP (3 years), meaning that mean age equivalents (AE) could not be calculated for this test; raw scores were therefore used in analyses. As the CSIM is not standardised on typical children, no age equivalents were available for 
this test. As can be seen from table 1b, there was a wide range in level of cognitive ability, with full scale cognitive scores ranging from age equivalents of 2.58 to 7.17 years. A similar range was found for the receptive vocabulary measure (BPVS-II), ranging from AEs of 2.83 years to 7.20 years. However the highest score achieved on the CELF Receptive Language measure was only AE 4.83 years. Participant 12 was unable to complete the CELF, he is therefore not included in comparisons of CELF scores with other measures.

\section{Insert tables $1 a$ and $1 b$ around here}

\section{Language and cognitive measures}

Pearson's correlations were used to test for significant correlations with chronological age and between all the measures. Age equivalents were used for the language and cognitive measures. A threshold of $\mathrm{p}<.01$ was taken as significant unless otherwise stated. None of the language or cognitive measures correlated with chronological age. Table 2 show significant correlations between the measures of language and cognition. As can be seen in table 2, the language measures, BPVS-II and CELF, correlated highly with each other. Within the CELF, expressive language correlated highly with receptive language. The BPVS-II receptive vocabulary measure correlated highly with the verbal mental age (VMA) composite of the WPSSI-III but the CELF correlated only weakly with VMA ( $\mathrm{r}=.623 ; \mathrm{p}=.023)$. WPPSI Performance mental age (PMA) did not correlate with any of the language measures. This suggests that receptive and expressive language are related but non-verbal ability is independent of other skills. 


\section{Insert table two around here}

Paired t-tests were used to determine, in terms of age equivalents, which language and cognitive measures showed relatively greater levels of impairment. A Bonferroni correction was applied, adjusting the significance level to $p<.003$. WPPSI Performance MA was greater than verbal MA in 10 out the 15 children and equivalent in two others. Despite this, there was no statistically significant difference between PMA and VMA $(\mathrm{t}(13)=-3.073, p=.009)$ although non-verbal cognitive skills were in advance of language skills (PMA and CELF total: $(\mathrm{t}(12)=-6.329, p<.0005)$. An exception to this was receptive vocabulary skills as measured by the BPVS-II which were commensurate with cognitive skills (VMA [t(13)=1.466, $p=.166]$; PMA [t(13)=-1.851, $p=.087]$ and FSMA [t(13)=$.543, p=.596])$.

BPVS-II receptive vocabulary was significantly in advance of CELF expressive and receptive language $(\mathrm{t}(13)=5.453, p<.0005$ and $\mathrm{t}(13)=3.750, p=.002$ respectively) with CELF receptive language in advance of CELF expressive language $(\mathrm{t}(13)=-4.067$, $p=.001)$.

\section{Speech measures}

As two thirds (10) of the children with DS failed to meet the basal age equivalent of $3 ; 0$ years in the DEAP percentage consonants correct, age equivalents could not be reported for this measure. This suggests that the majority of the children with DS presented with very severe speech disorders. In order to determine whether a relationship existed between cognitive, language and speech skills, the measures from the DEAP and CSIM 
were correlated with the language and cognitive measures. Since floor age equivalent results were obtained in the DEAP, raw or percentage scores were used for the calculations. Table 3 shows correlations between the speech and oromotor measures.

\section{Insert table 3 around here}

All of the measures from the DEAP, PCC, PVC, PPC and SvC, correlated highly with each other (all $p<.0005$ ). The oromotor measure, the Robbins and Klee, correlated highly with PCC, PPC and SvC and weakly with PVC. Results from the CSIM correlated highly with all of the measures from the DEAP and with the Robbins Klee. This suggests that children with poorer oromotor skills (speech and non-speech) produced less intelligible speech with more errors.

PCC did not correlate with any of the language measures nor did the CSIM, although the CELF receptive did approach significance $(\mathrm{r}=.577, p=.063)$ suggesting that speech disorder is independent of language ability. Moreover, PCC did not correlate with performance, verbal or full-scale mental age and there was no correlation between the CSIM and verbal, performance or full-scale mental age.

\section{Phonological and Phonetic Analyses}

Twenty-nine different processes were identified in the single word productions of the DEAP phonology subtest. A total of 1,012 errors was produced by participants $(\mathrm{M}=67.47, \mathrm{SD}=36.33)$ out of which 77 speech errors (7.61\% of total errors) were unclassifiable due to their unusual nature. Of these 29 different processes, 23 were evident at least three times in one or more child's speech. Figure 1 shows the frequency 
of the different phonological processes; Figure 2 shows the number of children producing each process at least three times.

\section{Insert Figure 1 here}

Insert Figure 2 here

Cluster reduction was the most common process evidenced $(13.64 \%$ of the errors, 12 children), followed by the other structural simplification processes: final consonant deletion $(12.85 \%, 13$ children), initial consonant deletion (10.47\%, 10 children) and then gliding $(6.32 \%, 10$ children). Despite this there was no significant difference between the number of systemic (i.e. substitutions, for example velar fronting) and structural errors $(\mathrm{t}(14)=2.078, p=.057)$. The majority of processes $(66.23 \%$, paired samples t-test, $\mathrm{t}(14)=2.603, p=.021)$ were those commonly found in younger typically developing children, as defined by Dodd et al. (2002), suggesting mainly a delayed pattern of development. However, all of the children also presented with atypical or nondevelopmental errors. Only one child had more atypical (75\%) than typical errors. This particular child's speech was characterised by deletion of word initial fricatives, production of other fricatives as ingressives, and production of word-final stops as ejectives. In the group as a whole, there was no correlation between the number of typical errors and the number of atypical errors $(r=.330 ; p=.230)$ suggesting that contrary to what might be expected, children with more developmental errors did not also present with more atypical errors. Table 4 shows examples of typical, atypical and unclassifiable (also atypical) errors. 


\section{Discussion.}

The children with DS presented with widely varying ability. Full scale cognitive ability was in the range of 2.58 to 7.17 years, confirming results of earlier studies (Chapman and Hesketh, 2001). Results of the language and cognitive tests broadly support the literature which suggests that children and young people with Down's syndrome present with marked deficits in expressive language (Chapman, 2006). Expressive language was impaired not only in relation to non-verbal cognitive ability but also in relation to receptive language. Since many of the children were highly unintelligible, assessment of expressive language was difficult and its possible that this discrepancy is the result of testing difficulties rather than an actual difference.

In contrast to previous research, we did not find a relative strength in receptive vocabulary compared to non-verbal ability but we did find that receptive vocabulary was superior to expressive and receptive language. As predicted, language skills correlated highly but, rather unexpectedly, language skills did not correlate with performance or verbal mental age. Theoretically this is important because it suggests that the language impairment in DS is not simply a result of cognitive delay but due to some other factor and is, essentially, a 'specific' language impairment. Clinically this is important because it suggests that language intervention may be warranted in people with DS who present with a discrepancy between language and cognition.

Severe speech disorders were evident in the majority of the participants with most children performing below the basal age equivalent on the DEAP. Moreover, on average intelligibility ratings, as measured by the CSIM, were only 52\%, suggesting that around half of the words spoken by the children with DS were unintelligible. People with DS 
generally produce words more accurately on imitation rather than spontaneous production (Dodd, 1995), suggesting that if anything the scores in the CSIM underestimate how intelligible these children are out of context. Since the children in this study were recruited for the purpose of interventions designed to increase intelligibility, they may represent a group of children with usually severe speech disorders. That is, families of children with very intelligible speech were not likely to present themselves for inclusion in an intervention study aiming to improve speech. However, Kumin (1994) reported that $95 \%$ of children with DS have difficulty being understood sometimes or frequently and since the participants in this study had disorders ranging from mild to severe it is probable that they are within the $95 \%$.

Most of the participants did not meet the basal age equivalent of the DEAP (3 years). This makes it difficult to determine statistically whether speech is more impaired than language or cognitive skills, but given that most of the children with DS performed above an age equivalent of 3 years in the language and cognitive assessments, this seems likely to be the case. Furthermore, severity of speech disorder, as measured by both the DEAP and the CSIM, did not correlate with any of the language or cognitive measures, suggesting that the speech impairment is caused by some factor other than language or cognitive delay. However, since the children in this study were aged 9 to 18 , it is possible that a relationship does exist in younger children. For example, delays in cognition and language early in development may cause delayed speech which then fails to develop in tandem with increasing language and cognitive skills. Alternatively, reduced intelligibility may be due to reduced oromotor skills, confirmed by correlations 
between the measure of oromotor function, percentage consonants correct and the speech intelligibility measure.

The intelligibility measure correlated highly with percentage consonants correct. This suggests that children who perform poorly in the phonology test are also less intelligible to an unfamiliar listener. It also gives confidence that single word phonology tests, which are often used to diagnose speech disorders, are reflective of more general intelligibility, an aspect of speech which is often not measured in the speech and language therapy clinic.

Twenty-nine different processes were identified in the speech of the children with DS, with 23 of these occurring at least 3 times in at least one child's speech. Only 11 out of these 29 processes $(37.93 \%)$ were processes found in typically developing children. A further 65 errors were not able to be classified as a known process (Grunwell, 1985) because of their unusual or idiosyncratic nature.

Structural processes (consonant deletions) were very common, including the nondevelopmental process of initial consonant deletion. In the most severely affected children, words were produced without any consonants at all, preserving only the vowel in the case of a CVC structure. Developmentally, the whole word phase, characterised by structural simplifications, precedes the systematic simplifications phase in which systematic substitutions dominate (Stackhouse and Wells, 1997). This suggests an element of delay in children with DS. Where structural simplifications, such as final consonant deletion are evident, phonotactic therapy (Velleman, 2002) can increase the phonotactic frames evident in a child's speech, leading to increased intelligibility, suggesting that phonotactic therapy may be one useful approach for people with DS. 
Overall there was a greater incidence of those processes usually found in typical development and all of the children bar one had more developmental than nondevelopmental errors. This could be interpreted as a case of delay rather than disorder (Van Borsel, 1996). However, given that all of the children with DS had at least one atypical error, it seems premature to conclude this. Moreover, the severity and pervasiveness of the delayed error patterns may in itself be enough to suggest that speech in DS is severely disordered. When a child presents with a single disordered speech error in the face of many delayed patterns this is usually diagnosed by speech and language therapists as a speech disorder. For example, four of the children with DS presented with phoneme specific nasal emission, a rare functional articulation disorder where air is emitted through the nose rather than the mouth when saying specific sounds. Since the nasal emission is confined to certain phonemes (usually sibilants), the cause cannot be organic; also, since there is no loss of contrast, this error in itself may not affect intelligibility. However, the resultant speech is so unusual sounding that it may impact on social acceptance. Dodd and Thompson (2001) suggest that inconsistency in the speech of children with DS may result from incomplete phonological representations, and it seems possible that errors like phoneme specific nasal emission may also be the result of underspecified phonological representations. This would be evidence for disorder rather than delay in DS.

Dodd and Thompson (2001) conclude that the inconsistency in the children with DS cannot be due to reduced oromotor skills because their participants with DS had similar levels of percentage phonemes correct as a control group of children with inconsistent phonological disorder. Since Dodd and Thompson (2001) did not 
specifically measure oromotor skills this is a problematic conclusion. The children in the present study did present with deficits in oromotor skills (as measured by the Robbins and Klee, 1987), with most children having difficulty combining and sequencing phonemes in the diadochokinetics tasks in the assessment. Dodd et al (2002) suggest that inconsistency combined with oromotor deficits may warrant a diagnosis of dyspraxia. Its possible that in the earlier study by Dodd and Thompson (2001) children with DS presented with similar levels of percentage phonemes correct to children with inconsistent phonological disorder but the inconsistency had a different cause. Future studies should seek to investigate both inconsistency and oromotor skills.

The possibility of dyspraxia as a diagnosis in DS has been little investigated. Although the present study was not specifically designed to investigate this, there is some evidence that a least some of the children with DS present with symptoms usually found in dyspraxia (Kumin, 2006). For example, processes that are hard to classify have been suggested to be one of the distinguishing features of dyspraxia (ASHA, 2007) and there were many examples of this in the data. Moreover, most of the children omitted sounds and syllables (Rupela and Manjula, 2007) and many had a limited repertoire of phonemes. In some cases, the repertoire was so severely reduced that many words consisted of vowels only. Dyspraxia in itself is a controversial diagnosis, with no single validated list of diagnostic criteria (ASHA, 2007). However, most criteria for dyspraxia would exclude neuromuscular deficits such as the hypotonicity found in DS, suggesting that the speech disorder in DS cannot be classified a straightforward case of dyspraxia. Nevertheless, the speech disorders reported here are not wholly accounted for by phonological delays/disorders or hypotonicity and the children do present with 
difficulties in motor planning and programming, as demonstrated by poor performance in the diadochokinesis tasks in the oromotor assessment. These elements are incorporated in the psycholinguistic framework (Stackhouse and Wells, 1997) under "motor programming". The psycholinguistic framework is one approach for profiling individual children's speech processing strengths and weaknesses in both the input and output modalities. Although we did not test the integrity of children's phonological representations here, there is some evidence in the literature that these are impaired in DS. For example, Snowling, Hulme and Mercer (2002) found deficits in rime awareness, suggesting that investigation of input skills is an important area for both future research and for differential diagnosis and intervention planning.

\section{Conclusions}

Children and adolescents with Down's syndrome present with deficits in receptive and expressive language that is not wholly accounted for by their cognitive delay. While receptive vocabulary is a strength in comparison to language skills, it is unclear whether it is more advanced compared to non-verbal cognitive skills.

Speech is particularly impaired in DS. The finding that all the children with DS showed at least one atypical or non-developmental speech error leads us to believe that children with DS present with speech disorders characterised by atypical errors alongside many developmental errors. The cause of the speech disorder in DS remains unclear. However, anecdotal reports that the more unintelligible children are not necessarily the most cognitively or linguistically impaired was confirmed by the lack of any correlation between our speech measures and either cognitive or language measures. 
This suggests that the cause of the speech disorder is not merely a cognitive delay nor is it directly related to concurrent language ability, and as such differs in different individuals. Underspecified phonological representations may be responsible in some children, whereas others seem to have difficulty with the motor control required for speech, similar to dyspraxia. From a clinical perspective, it nevertheless seems clear that

the speech disorder in DS warrants intervention. Clinicians should apply their skills in the differential diagnosis of speech disorders to children with DS, allowing interventions to target the cause of the disorder in each individual.

\section{Acknowledgements}

This research was supported by a grant from the Medical Research Council (G0401388). Thanks are extended to Ann Robertson for administering the cognitive assessments; Annabel Allen and Marjorie Douglas for help scoring the assessments; Down's Syndrome Scotland for their help in recruiting participants; and the children and their parents for their goodwill, patience and contributions to the study. 


\section{References}

Abbeduto, L., Pavetto, M., Kesin, E., Weissman, M., Karadottir, S., O’Brien, A. and CAwthon,S., 2001, The linguistic and cognitive profile of Down syndrome: Evidence from a comparison with fragile X syndrome. Down Syndrome Research and Practice, 7: 9-15.

AmericAn SpeEch-LAnguage-HeARIng Association, 2007, Childhood Apraxia of Speech [Technical Report]. Available from www.asha.org/policy.

Barnes, E., Roberts, J., Mirrett, P., Sideris, J. and Misenheimer, J., 2006, A Comparison of Oral Structure and Oral-Motor Function in Young Males with Fragile X Syndrome and Down Syndrome. Journal of Speech, Language and Hearing Research 49:903-917.

Canfield, MA., Honein, MA., Yuskiv, N., Xing, J., Mai, CT., Collins, JS., Devine, O., PETRIni, J., RAMADHANi, TA., HobBS, CA. and KiRBY, RS., 2006, National estimates and race/ethnic-specific variation of selected birth defects in the United States, 1999-2001. Birth Defects Res A Clin Mol Teratol, 76:747-56.

Chapman, R., 2006, Language learning in Down syndrome: The speech and language profile compared to adolescents with cognitive impairment of unknown origin. Down Syndrome Research and Practice, 10: 61-66.

Chapman, R. and Hesketh, L., 2001, Language, cognition, and short-term memory in individuals with Down syndrome. Down Syndrome Research and Practice, 7, 1-7

DoDD, B., 1995, Differential diagnosis and treatment of children with speech disorder. London: Whurr Publishers. 
Dodd, B., HuA, Z., Crosbie, S., and Holm, A., 2002, Diagnostic Evaluation of Articulation and Phonology. London: The Psychological Corporation.

DodD, B. and Thompson, L., 2001, Speech disorder in Down's syndrome. Journal of Intellectual Disability Research, 45: 308-316.

Dunn, L., Dunn, L., WhetTon, C., and Burley, J., 1997, British picture vocabulary scale second edition. Windsor: NFER-Nelson.

FRITH, U. and FrITH, C.D., 1974, Specific Motor disabilities in Down's Syndrome. Journal of Child Psychology and Psychiatry 15:293-301.

Grunwell, P., 1985, Phonological Assessment of Child Speech (PACS). Windsor: NFERNelson

Hickson., F, 1987, The Manchester Picture Test: A Summary. Manchester: University of Manchester.

Jarrold, C., Baddeley, A. and Philips, C., 2002, Verbal Short-Term Memory in Down Syndrome: A Problem of Memory, Audition, or Speech? Journal of Speech Language and Hearing Research, 45, 531-544

KumIN, L., 1994, Intelligibility of speech in children with Down syndrome in natural settings: parents' perspective. Perceptual Motor Skills, 78,307-13

KuMIN, L., 2006, Speech intelligibility and childhood verbal apraxia in children with Down syndrome. Down Syndrome Research and Practice, 10, 10-22.

LAWS, G., 2004, Contributions of phonological memory, language comprehension and hearing to the expressive language of adolescents and young adults with Down syndrome. Journal of Child Psychology and Psychiatry, 45, 1085-1095. 
LAws, G. and Bishop, D., 2004, Verbal deficits in Down's syndrome and specific language impairment: a comparison. International Journal of Language and Communication Disorders, 39, 423-451.

Miller, J. F., and LedDy, M., 1998, Down syndrome: the impact of speech production on language development. In R. Paul (Ed.), Communication and Language Intervention: Vol. 8. Exploring the Speech-Language Connection (pp. 163-177). Baltimore: Paul H. Brookes.

Miller, J., LedDy, M. and LeAVITT, L., 1999, Improving the communication of people with Down syndrome. Baltimore: Paul H. Brookes Pub.

Roberts, J., Long, S., Malkin, C., Barnes, E., Skinner, M., Hennon, E. and Anderson, K., 2005, A Comparison of Phonological Skills of Boys with Fragile X Syndrome and Down Syndrome. Journal of Speech, Language, and Hearing Research, 48, 980-995.

Robbins, J. and KLEE, T., 1987, Clinical assessment of oropharyngeal motor development in young children. Journal of Speech and Hearing Disorders, 52, 271-277.

RoNDAL, J. and EDWARDS, S., 1997, Language in Mental Retardation. Whurr: London.

RoIzEN, N., 1997, Hearing loss in children with Down syndrome: a review. Down Syndrome Quarterly, 2, 1-4.

RoIZEN, N., 2002, Down Syndrome. In: Batshaw, M. (Ed) Children with disabilities, $5^{\text {th }}$ Ed. Baltimore, MD: Brookes, 361-376.

Rupela, V. and Manjula, R., 2007, Phonotactic patterns in the speech of children with Down syndrome. Clinical Linguistics and Phonetics, 21: 605-622

Snowling, M., Hulme, C., and Mercer, R., 2002, A deficit in rime awareness in children with Down syndrome. Reading and Writing, 15: 471-495 
Spano, M., Mercuri, E., Rando, T., Panto, T., Gagliano, A., Henderson, S. and GuZZETTA, F., 1999, Motor and Perceptual-motor competence in children with Down syndrome: variation in performance with age. European Journal of Paediatric Neurology, 3: 7-13.

Spender, Q., Dennis, J., Stein, A., Cave, D., Percy, E. and Reilly, S., 1995, Impaired oralmotor function in children with Down's syndrome: a study of three twin pairs. European Journal of Disorders of Communication, 30, 87-97.

Stackhouse, J. and Wells, B., 1997, Children's speech and literacy difficulties, a psycholinguistic framework. London: Whurr Publishers.

Stoel-Gammon C.,1980, Phonological analysis of four Down's syndrome children. Applied Psycholinguistics 1:31-48.

VAN BoRSEL, J., 1996, Articulation in Down's syndrome adolescents and adults. European Journal of Disorders of Communication, 31, 414-444.

Velleman, S., 2002, Phonotactic Therapy. Seminars in Speech and Language, 23, 43-55.

WeSCHLER, D., 2003, Wechsler Primary and Preschool Scale of Intelligence- Third UK Edition. London: The Psychological Corporation.

WIIG, E., SECORD, W. and SEMEL, E., 1992, Clinical Evaluation of Language FundamentalsPreschool UK. London: The Psychological Corporation.

WiLcox, K., and MorRIS, S., 1999, Children's Speech Intelligibility Measure (CSIM). London: The Psychological Corporation. 
Table 1a: Standardised Assessment Results: Individual

\begin{tabular}{|c|c|c|c|c|c|c|c|c|c|c|c|c|c|c|c|}
\hline \multirow[b]{2}{*}{ Participant } & \multirow[b]{2}{*}{ Age } & \multirow[b]{2}{*}{ SEX } & \multicolumn{5}{|c|}{ DEAP } & \multirow[b]{2}{*}{ CSIM } & \multirow[b]{2}{*}{$\begin{array}{c}\text { BPVS- } \\
\text { II }\end{array}$} & \multicolumn{2}{|c|}{ CELF } & \multirow[b]{2}{*}{ RK } & \multicolumn{3}{|c|}{ WPPSI } \\
\hline & & & & PCC & PVC & PPC & $\mathrm{SvC}$ & & & CELFE & CELFC & & VMA & PMA & FMA \\
\hline 1 & $11 ; 5$ & F & $\underset{\%}{\text { Age Eq }}$ & $\begin{array}{c}<3 ; 0 \\
57.00\end{array}$ & $\begin{array}{c}<3 ; 0 \\
77.00\end{array}$ & $\begin{array}{c}<3 ; 0 \\
64.00\end{array}$ & $\begin{array}{c}<3 ; 0 \\
20.00\end{array}$ & $\begin{array}{c}* \\
72.00\end{array}$ & $\begin{array}{c}5 ; 5 \\
32.74\end{array}$ & $\begin{array}{c}3 ; 0 \\
32.08\end{array}$ & $\begin{array}{c}3 ; 11 \\
70.97\end{array}$ & $\begin{array}{c}* \\
78.85\end{array}$ & $\begin{array}{c}4 ; 1 \\
*\end{array}$ & $\begin{array}{c}6 ; 4 \\
*\end{array}$ & $\begin{array}{c}5 ; 3 \\
*\end{array}$ \\
\hline 2 & $10 ; 1$ & M & $\begin{array}{c}\text { Age Eq } \\
\%\end{array}$ & $\begin{array}{l}<3 ; 0 \\
31.21\end{array}$ & $\begin{array}{l}<3 ; 0 \\
47.30\end{array}$ & $\begin{array}{l}<3 ; 0 \\
36.74\end{array}$ & $\begin{array}{l}<3 ; 0 \\
50.00\end{array}$ & $\begin{array}{c}* \\
32.00\end{array}$ & $\begin{array}{c}3 ; 0 \\
16.07\end{array}$ & $\begin{array}{c}2 ; 8 \\
24.53\end{array}$ & $\begin{array}{c}3 ; 5 \\
61.29\end{array}$ & $\begin{array}{c}* \\
66.35\end{array}$ & $\begin{array}{c}3 ; 7 \\
*\end{array}$ & $\begin{array}{l}4 ; 4 \\
*\end{array}$ & $\begin{array}{c}3 ; 11 \\
*\end{array}$ \\
\hline 3 & $16 ; 6$ & M & $\underset{\%}{\text { Age Eq }}$ & $\begin{array}{c}<3 ; 0 \\
18.18\end{array}$ & $\begin{array}{c}<3 ; 0 \\
75.00\end{array}$ & $\begin{array}{c}<3 ; 0 \\
37.90\end{array}$ & $\begin{array}{c}<3 ; 0 \\
10.00\end{array}$ & $\begin{array}{c}* \\
20.00\end{array}$ & $\begin{array}{c}6 ; 10 \\
41.67\end{array}$ & $\begin{array}{c}3 ; 10 \\
55.66\end{array}$ & $\begin{array}{c}4 ; 0 \\
72.58\end{array}$ & $\begin{array}{c}* \\
51.92\end{array}$ & $\begin{array}{c}7 ; 2 \\
*\end{array}$ & $\begin{array}{l}7 ; 2 \\
*\end{array}$ & $\begin{array}{c}7 ; 2 \\
*\end{array}$ \\
\hline 4 & $16 ; 5$ & M & $\begin{array}{c}\text { Age Eq } \\
\%\end{array}$ & $\begin{array}{r}<3 ; 0 \\
49.32\end{array}$ & $\begin{array}{c}3 ; 6 \\
91.14\end{array}$ & $\begin{array}{l}<3 ; 0 \\
64.00\end{array}$ & $\begin{array}{l}<3 ; 0 \\
33.33\end{array}$ & $\begin{array}{c}* \\
42.86\end{array}$ & $\begin{array}{c}2 ; 11 \\
14.88\end{array}$ & $\begin{array}{c}2 ; 6 \\
13.20\end{array}$ & $\begin{array}{c}2 ; 9 \\
37.10\end{array}$ & $\begin{array}{c}* \\
61.54\end{array}$ & $\begin{array}{l}2 ; 7 \\
*\end{array}$ & $\begin{array}{c}2 ; 7 \\
*\end{array}$ & $\begin{array}{c}2 ; 7 \\
*\end{array}$ \\
\hline 5 & $10 ; 11$ & M & $\underset{\%}{\text { Age Eq }}$ & $\begin{array}{c}3 ; 0 \\
80.00\end{array}$ & $\begin{array}{l}4 ; 0 \\
100\end{array}$ & $\begin{array}{l}<3 ; 0 \\
82\end{array}$ & $\begin{array}{c}3 ; 0 \\
75.00\end{array}$ & $\begin{array}{c}* \\
66.00\end{array}$ & $\begin{array}{c}5 ; 2 \\
31.55\end{array}$ & $\begin{array}{c}3 ; 6 \\
46.23\end{array}$ & $\begin{array}{c}4 ; 2 \\
77.42\end{array}$ & $\begin{array}{c}* \\
81.73\end{array}$ & $\begin{array}{c}5 ; 4 \\
*\end{array}$ & $\begin{array}{c}5 ; 9 \\
*\end{array}$ & $\begin{array}{c}5 ; 4 \\
*\end{array}$ \\
\hline 6 & $14 ; 11$ & M & $\underset{\%}{\text { Age Eq }}$ & $\begin{array}{r}<3 ; 0 \\
48.98\end{array}$ & $\begin{array}{c}<3 ; 0 \\
78.21\end{array}$ & $\begin{array}{r}<3 ; 0 \\
59.11\end{array}$ & $\begin{array}{l}<3 ; 0 \\
9.09\end{array}$ & $\begin{array}{c}* \\
46.00\end{array}$ & $\begin{array}{c}7 ; 3 \\
44.05\end{array}$ & $\begin{array}{c}4 ; 0 \\
66.04\end{array}$ & $\begin{array}{c}4 ; 10 \\
87.10\end{array}$ & $\begin{array}{c}* \\
69.23\end{array}$ & $\begin{array}{c}5 ; 1 \\
*\end{array}$ & $\begin{array}{c}7 ; 2 \\
*\end{array}$ & $\begin{array}{c}6 ; 2 \\
*\end{array}$ \\
\hline 7 & $13 ; 0$ & M & $\begin{array}{c}\text { Age Eq } \\
\%\end{array}$ & $\begin{array}{c}4 ; 0 \\
87.92\end{array}$ & $\begin{array}{l}4 ; 0 \\
100\end{array}$ & $\begin{array}{c}4 ; 0 \\
92.12\end{array}$ & $\begin{array}{l}<3 ; 0 \\
66.67\end{array}$ & $\begin{array}{c}* \\
82.00\end{array}$ & $\begin{array}{c}6 ; 3 \\
38.10\end{array}$ & $\begin{array}{c}4 ; 0 \\
60.38\end{array}$ & $\begin{array}{c}4 ; 6 \\
83.87\end{array}$ & $\begin{array}{c}* \\
91.35\end{array}$ & $\begin{array}{c}6 ; 3 \\
*\end{array}$ & $\begin{array}{l}6 ; 1 \\
*\end{array}$ & $\begin{array}{c}5 ; 11 \\
*\end{array}$ \\
\hline 8 & $18 ; 8$ & M & $\underset{\%}{\text { Age Eq }}$ & $\begin{array}{c}3 ; 0 \\
79.86\end{array}$ & $\begin{array}{l}4 ; 0 \\
100\end{array}$ & $\begin{array}{c}3 ; 6 \\
87.00\end{array}$ & $\begin{array}{c}3 ; 6 \\
77.78\end{array}$ & $\begin{array}{c}* \\
81.25\end{array}$ & $\begin{array}{c}4 ; 3 \\
26.19\end{array}$ & $\begin{array}{c}3 ; 5 \\
45.28\end{array}$ & $\begin{array}{c}4 ; 0 \\
72.58\end{array}$ & $\begin{array}{c}* \\
81.73\end{array}$ & $\begin{array}{c}5 ; 3 \\
*\end{array}$ & $\begin{array}{c}4 ; 1 \\
*\end{array}$ & $\begin{array}{c}4 ; 10 \\
*\end{array}$ \\
\hline 9 & $15 ; 6$ & M & $\begin{array}{c}\text { Age Eq } \\
\%\end{array}$ & $\begin{array}{c}3 ; 0 \\
79.86\end{array}$ & $\begin{array}{l}4 ; 0 \\
100\end{array}$ & $\begin{array}{c}3 ; 6 \\
86.64\end{array}$ & $\begin{array}{c}3 ; 6 \\
77.78\end{array}$ & $\begin{array}{c}* \\
54.00\end{array}$ & $\begin{array}{c}5 ; 10 \\
35.12\end{array}$ & $\begin{array}{c}3 ; 3 \\
39.62\end{array}$ & $\begin{array}{c}4 ; 3 \\
80.65\end{array}$ & $\begin{array}{c}* \\
72.12\end{array}$ & $\begin{array}{l}5 ; 6 \\
*\end{array}$ & $\begin{array}{c}5 ; 4 \\
*\end{array}$ & $\begin{array}{c}5 ; 3 \\
*\end{array}$ \\
\hline 10 & $15 ; 9$ & F & $\underset{\%}{\text { Age Eq }}$ & $\begin{array}{l}<3 ; 0 \\
48.30\end{array}$ & $\begin{array}{c}<3 ; 0 \\
79.49\end{array}$ & $\begin{array}{r}<3 ; 0 \\
59.11\end{array}$ & $\begin{array}{c}<3 ; 0 \\
42.86\end{array}$ & $\begin{array}{c}* \\
42.00\end{array}$ & $\begin{array}{c}3 ; 1 \\
16.67\end{array}$ & $\begin{array}{c}2 ; 7 \\
28.30\end{array}$ & $\begin{array}{c}3 ; 1 \\
33.87\end{array}$ & $\begin{array}{c}* \\
68.27\end{array}$ & $\begin{array}{l}2 ; 7 \\
*\end{array}$ & $\begin{array}{l}4 ; 4 \\
*\end{array}$ & $\begin{array}{c}3 ; 9 \\
*\end{array}$ \\
\hline 11 & $15 . ; 8$ & F & $\underset{\%}{\text { Age Eq }}$ & $\begin{array}{r}<3 ; 0 \\
58.22\end{array}$ & $\begin{array}{c}<3 ; 0 \\
87.01\end{array}$ & $\begin{array}{c}<3 ; 0 \\
68.16\end{array}$ & $\begin{array}{c}<3 ; 0 \\
36.36\end{array}$ & $\begin{array}{c}* \\
36.73\end{array}$ & $\begin{array}{c}3 ; 3 \\
19.64\end{array}$ & $\begin{array}{c}2 ; 7 \\
29.25\end{array}$ & $\begin{array}{c}3 ; 1 \\
32.26\end{array}$ & $\begin{array}{c}* \\
70.19\end{array}$ & $\begin{array}{c}3 ; 7 \\
*\end{array}$ & $\begin{array}{c}6 ; 0 \\
*\end{array}$ & $\begin{array}{c}4 ; 9 \\
*\end{array}$ \\
\hline 12 & $17 ; 8$ & M & $\underset{\%}{\text { Age Eq }}$ & $\begin{array}{c}<3 ; 0 \\
32.00\end{array}$ & $\begin{array}{l}<3 ; 0 \\
84.42\end{array}$ & $\begin{array}{c}<3 ; 0 \\
50.45\end{array}$ & $\begin{array}{c}<3 ; 0 \\
30.00\end{array}$ & $\begin{array}{c}* \\
36.17\end{array}$ & $\begin{array}{c}2 ; 10 \\
13.10\end{array}$ & $*$ & $*$ & $\begin{array}{c}* \\
56.73\end{array}$ & $\begin{array}{c}2 ; 9 \\
*\end{array}$ & $\begin{array}{c}6 ; 10 \\
*\end{array}$ & $\begin{array}{c}4 ; 9 \\
*\end{array}$ \\
\hline 13 & $17 ; 5$ & M & $\underset{\%}{\text { Age Eq }}$ & $\begin{array}{c}<3 ; 0 \\
12.93\end{array}$ & $\begin{array}{c}<3 ; 0 \\
52.56\end{array}$ & $\begin{array}{r}<3 ; 0 \\
26.67\end{array}$ & $\begin{array}{l}<3 ; 0 \\
0.00\end{array}$ & $\begin{array}{c}* \\
24.00\end{array}$ & $\begin{array}{c}3 ; 3 \\
19.05\end{array}$ & $\begin{array}{c}3 ; 0 \\
31.13\end{array}$ & $\begin{array}{c}2 ; 10 \\
40.32\end{array}$ & $\begin{array}{c}* \\
54.80\end{array}$ & $\begin{array}{c}3 ; 1 \\
*\end{array}$ & $\begin{array}{c}7 ; 2 \\
*\end{array}$ & $\begin{array}{c}5 ; 2 \\
*\end{array}$ \\
\hline 14 & $10 ; 2$ & M & $\underset{\%}{\text { Age Eq }}$ & $\begin{array}{c}3 ; 0 \\
81.63\end{array}$ & $\begin{array}{l}4 ; 0 \\
100\end{array}$ & $\begin{array}{c}3 ; 6 \\
88.05\end{array}$ & $\begin{array}{c}3 ; 6 \\
80.00\end{array}$ & $\begin{array}{c}* \\
84.09\end{array}$ & $\begin{array}{c}6 ; 10 \\
41.67\end{array}$ & $\begin{array}{c}4 ; 5 \\
67.92\end{array}$ & $\begin{array}{c}3 ; 10 \\
69.35\end{array}$ & $\begin{array}{c}* \\
90.38\end{array}$ & $\begin{array}{l}3 ; 7 \\
*\end{array}$ & $\begin{array}{c}4 ; 11 \\
*\end{array}$ & $\begin{array}{c}4 ; 3 \\
*\end{array}$ \\
\hline 15 & $9 ; 7$ & M & $\underset{\%}{\text { Age Eq }}$ & $\begin{array}{r}<3 ; 0 \\
42.00\end{array}$ & $\begin{array}{c}3 ; 0 \\
89.74\end{array}$ & $\begin{array}{c}<3 ; 0 \\
58.67\end{array}$ & $\begin{array}{r}<3 ; 0 \\
45.45\end{array}$ & $\begin{array}{c}* \\
66.00\end{array}$ & $\begin{array}{c}5 ; 6 \\
33.33\end{array}$ & $\begin{array}{c}4 ; 0 \\
59.43\end{array}$ & $\begin{array}{c}4 ; 9 \\
87.10\end{array}$ & $\begin{array}{c}* \\
84.62\end{array}$ & $\begin{array}{c}4 ; 8 \\
*\end{array}$ & $\begin{array}{c}5 ; 3 \\
*\end{array}$ & $\begin{array}{c}4 ; 9 \\
*\end{array}$ \\
\hline
\end{tabular}


Table 1b: Standardised Assessment Results: Group

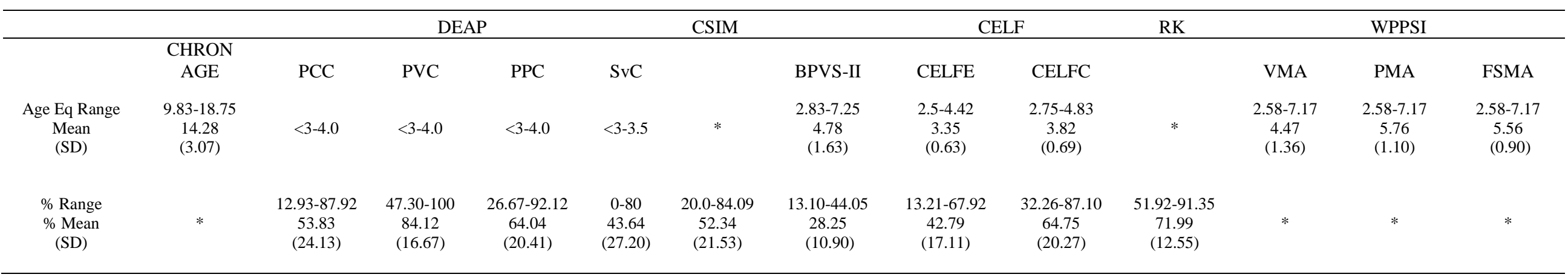

DEAP=Diagnostic Evaluation of Articulation and Phonology; PCC $=$ Percentage Consonants Correct; PVC $=$ Percentage Vowels Correct; $\mathrm{PPC}=$ Percentage Phonemes Correct; $\mathrm{SvC}=$ Single Word $/$ Connected speech agreement.

CSIM= Children's Speech Intelligibility Measure

BPVS-II= British Picture Vocabulary Scale-II

$\mathrm{CELF}=$ Clinical Evaluation of Language Fundamentals-Preschool UK; CELF-E $=$ CELF Expressive Language; CELFC $=$ CELF Receptive Language

RK= Robbins and Klee Clinical assessment of oropharyngeal motor development in young children.

WPPSI= Wechsler Preschool and Primary Scale of Intelligence; VMA=Verbal Mental Age; PMA= Performance Mental Age; FSAE= Full-Scale Mental Age 
Table 2: Correlations: Language and Cognitive Measures.

\begin{tabular}{lccccc}
\hline & BPVS-II & CELF & CELF Exp & CELF Rec & VMA \\
\hline Chron Age & $*$ & $*$ & $*$ & $*$ & $*$ \\
PMA & $*$ & $*$ & $*$ & $*$ & $*$ \\
VMA & $\mathrm{r}=.697 ; p=.006$ & $*$ & $*$ & $*$ & \\
CELF Rec & $\mathrm{r}=.826 ; p<.0005$ & $\mathrm{r}=.887 ; p<.0005$ & $\mathrm{r}=.786 ; p=.0001$ & & \\
CELFExp & $\mathrm{r}=.885 ; p<.0005$ & $\mathrm{r}=.967 ; p<.0005$ & & & \\
CELF & $\mathrm{r}=.875 ; p<.0005$ & & & & \\
\hline
\end{tabular}

PMA= Performance Mental Age (WPPSI)

$\mathrm{VMA}=$ Verbal Mental Age (WPPSI)

CELF Rec $=$ Clinical Evaluation of Language Fundamentals- receptive language

CELF Exp $=$ Clinical Evaluation of Language Fundamentals- expressive language $\mathrm{CELF}=$ Clinical Evaluation of Language Fundamentals- total language

* no significant correlation. 
Table 3: Correlations: Speech and oromotor measures

\begin{tabular}{lccccc}
\hline & PCC & PPC & PVC & SvC & RK \\
\hline Chron Age & $*$ & $*$ & $*$ & $*$ & $*$ \\
CSIM & $\mathrm{r}=.889 ; p<.0005$ & $\mathrm{r}=.876 ; p<.0005$ & $\mathrm{r}=.694 ; p=.012$ & $\mathrm{r}=.733 ; p=.007$ & $\mathrm{r}=.945 ; p<.005$ \\
RK & $\mathrm{r}=.826 ; p<.0005$ & $\mathrm{r}=.801 ; p<.0005$ & $\mathrm{r}=.620 ; p=.014$ & $\mathrm{r}=.720 ; p=.002$ & \\
SvC & $\mathrm{r}=.831 ; p<.0005$ & $\mathrm{r}=.811 ; p<.0005$ & $\mathrm{r}=.672 ; p=.002$ & & \\
PPC & $\mathrm{r}=.985 ; p<.0005$ & & & & \\
\hline
\end{tabular}

$\mathrm{PCC}=$ Percentage Consonants Correct (DEAP)

$\mathrm{PPC}=$ Percentage Phonemes Correct (DEAP)

$\mathrm{PVC}=$ Percentage Vowels Correct (DEAP)

$\mathrm{SvC}=$ Single words/connected speech agreement (DEAP)

$\mathrm{RK}=$ Robbins Klee, oromotor assessment

$\mathrm{CSIM}=$ Children's Speech Intelligibility Measure

* no significant correlation 
Table 4: Example transcriptions

\begin{tabular}{|c|c|c|c|}
\hline Target & Transcription & Error type & Process \\
\hline teeth & $\mathrm{ti}$ & typical & Final Consonant Deletion \\
\hline swing & SWIn & typical & Velar Fronting \\
\hline watch & Go $\chi$ & atypical & $\begin{array}{l}\text { Initial consonant: consonant harmony } \\
\text { Final Affricate: deaffricated and backed to uvular } \\
\text { position }\end{array}$ \\
\hline five & ใəł $\downarrow$ & atypical & $\begin{array}{l}\text { Initial consonant: glottal replacement } \\
\text { Diphthong: reduced and centralised } \\
\text { Final consonant: backed to alveolar, lateralised and } \\
\text { ingressive airstream }\end{array}$ \\
\hline thank you & ajuç & atypical & $\begin{array}{l}\text { Initial consonant: deleted } \\
\text { ykj: reduced to } j\end{array}$ \\
\hline
\end{tabular}


Figure 1: Phonological Processes

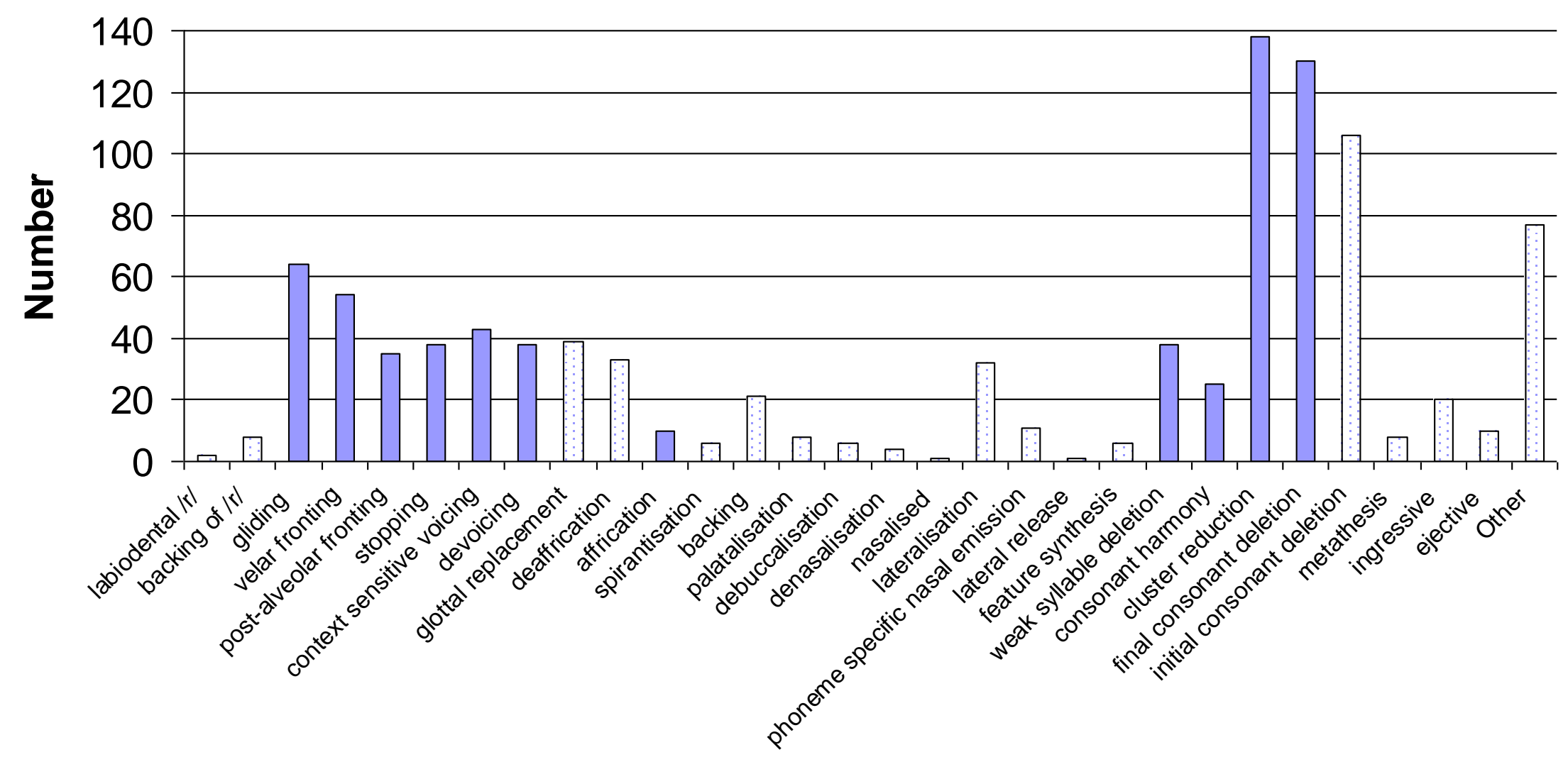

Type

Dark bars $=$ Typical Processes

Light bars $=$ Atypical Processes 
Figure 2.

\section{Error Types by Number of Children}

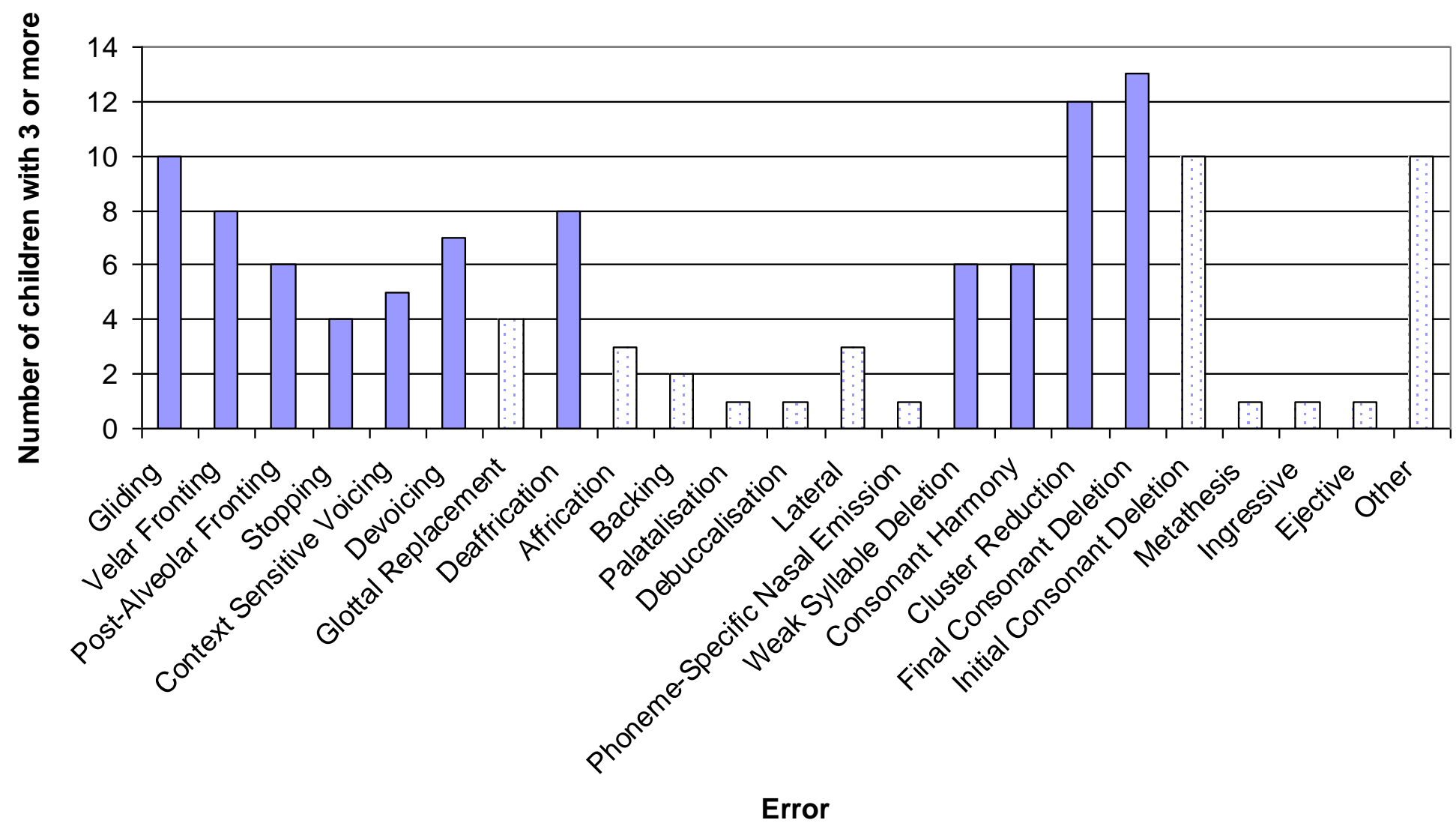

Dark bars $=$ Typical Processes

Light bars= Atypical Processes 